\title{
Clinical Evaluation of Lamprene (Geigy) A Preliminary Report ${ }^{*}$
}

\author{
E. R. KARURU \\ Medical Superintendent, Fiji Leprosy Hospital, Makogai, Fiji
}

\begin{abstract}
The brief case histories here reported of 18 patients with leprosy, in come cases of long standing, show that treatment with clofazimine (B 663, Lamprene) brought about, in all but one case, improvement which ranged from good to remarkable. It is suggested that the drug may be particularly useful in treating patients intolerant of DDS.
\end{abstract}

\section{INTRODUCTION}

Favourable reports of the action of Lamprene (clofazimine) in leprosy encouraged us to carry out an uncontrolled trial at the above hospital.

\section{PATIENTS}

The series consisted of 20 patients in the following groups who were given Lamprene between June and September, 1967: (1) 7 new patients who had not previously received any antileprotic drugs; (2) 4 patients who had been in hospital for 2 years or more and whose progress had been greatly retarded by persistent erythema nodosum leprosum (ENL); and (3) 9 patients who had relapsed on one or more occasions and whose condition was deteriorating despite treatment. The types of leprosy in these groups are shown in Table 1 .

TABLE 1

\begin{tabular}{lcccc}
\hline Type of disease & Group 1 & Group 2 & Group 3 & Totals \\
\hline Lepromatous & 2 & 3 & 4 & 9 \\
Dimorphous & 4 & 1 & 5 & 10 \\
Tuberculoid & 1 & - & - & 1 \\
Total & 7 & 4 & 9 & 20
\end{tabular}

Of the 20 patients, 12 were males and 8 females, the majority being Fijian (9) and Indian (6). The youngest was a 19 year old Fijian male, and the oldest an Indian female aged 61 .

*Received for publication December, 1969.

\section{PROCEDURE}

The usual taking of the case history was followed by routine blood tests, including haemoglobin estimation, blood red and white cell and differential counts, blood grouping, and examination for filaria. Serum protein estimation, but not electrophoresis, was done in 15 of the patients. Biopsies were performed, not less than 4 smears being taken from each patient. The Bacterial Index (B.I.) (Ridley, 1967) was checked regularly. Urine and stools were checked, and intestinal parasitoses treated before starting Lamprene therapy. Photographic records were taken before, during, and after the 12-month trial period. All patients were weighed initially and again at follow-up examination. Lamprene was given in a dosage of $700 \mathrm{mg}$ per week, that is $1 \times 100 \mathrm{mg}$ capsule daily for 5 days and 2 capsules on the sixth day; none was given on Sundays. Patients were examined as regularly as possible-during the first 6 months every one or 2 weeks-for clinical evaluation of lesions. Only 2 patients were unable to complete the trial: one because of bilateral tuberculous pleural effusions, and the other because he developed pneumonia; the other 18 patients completed the 12 -month preliminary trial, 6 in Group 1, 3 in Group 2, and 9 in Group 3.

\section{CASE REPORTS}

Group 1

T.M. 4104, male, Fiji-Solomon Islander, aged 28 , single, admitted to hospital 4 weeks before 
the trial started with a history of peripheral neuritis in both feet, progressive fatigue, puffiness of the face and ears, and oedema of the hands and feet. A diagnosis of lepromatous leprosy was made. During the first few months of treatment with Lamprene his condition failed to show any marked improvement, but during the sixth month his skin began to return to normal. Oedema then subsided slowly and he started to become active, improving steadily during the second 6 months of treatment when he was able to work in the hospital grounds. No ENL was experienced.

B.D. 4105, female, Indian, aged 61 years, admitted with dimorphous leprosy. At the end of the third month of Lamprene therapy there was definite improvement in the lesions, which gradually shrivelled during the fourth month. She continued to improve thereafter, without ENL reaction, and gained $9 \mathrm{lb} .(4.1 \mathrm{~kg})$ in weight.

Tara 4058, female, Indian, aged 19 years, admitted with nodular lepromatous leprosy. Again the initial response was slow, but after the first 3 months of treatment the discrete nodules over her back began to recede, followed after 6 months by those on the arms and face. During the last 2 months of the trial her clinical appearance improved remarkably (see Fig. 1, a, b). No ENI, reaction occurred during the

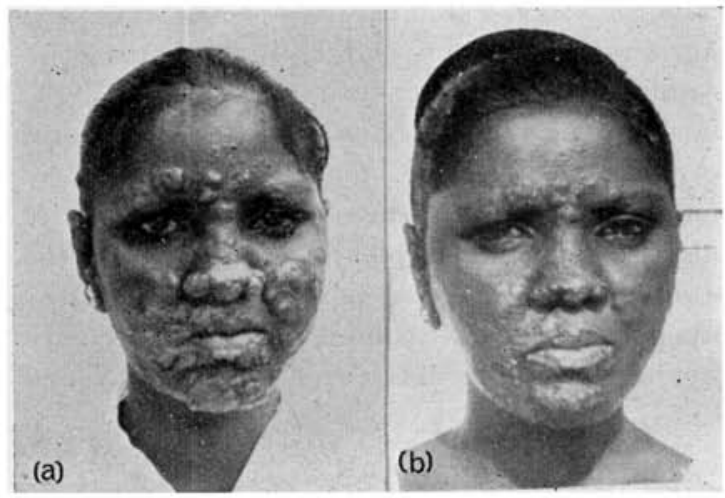

FIG. I

Tara, 4058. 19-year-old Indian girl of Group 1 type. (a) Before Lamprene treatment; (b) after treatment with Lamprene. 12-month trial period and the patient gained $12 \mathrm{lb} .(5.4 \mathrm{~kg})$ in weight. Because this patient's skin is normally very dark, the colour change seen in patients treated with Lamprene was barely noticeable.

T.T. 4108, male, Banaban, aged 21 years, was admitted suffering from pulmonary tuberculosis and dimorphous, lepromin-negative leprosy. He continued to receive antituberculosis chemotherapy as well as Lamprene throughout the trial. Both lung condition and leprosy improved satisfactorily, the skin over his lesions beginning to shrivel from the eighth week of treatment and the infiltration receding rapidly. His grip strength improved from $10 \mathrm{lb}(4.5 \mathrm{~kg})$ (left) and $20 \mathrm{lb}(9 \mathrm{~kg})$ (right) to 50 and $60 \mathrm{lb}(22.7$ and $27.2 \mathrm{~kg}$ ) respectively, and body weight from 128 to $152 \mathrm{lb} \quad(58$ to $69 \mathrm{~kg}$ ).

R.D. 4112, male, Indian, 52-year-old cane farmer, admitted with lepromin-positive tuberculoid leprosy (the only tuberculoid patient in this trial). Lesions were concentrated on the extremities and torso, and he had a right foot drop. Only 7 months after starting treatment with Lamprene no skin lesions could be seen, though the foot drop was still just noticeable.

A.L. 4114, 19-year-old male Fijian with very active dimorphous, pre-lepromatous leprosy; lepromin negative. After 3 weeks his condition deteriorated, with lesions becoming more active and oedema of the limbs and ears. Prednisolone, $10 \mathrm{mg}$ daily, was added to the Lamprene therapy in the sixth week to control a febrile exacerbation. Although he had lost $8 \mathrm{lb}(3.6 \mathrm{~kg})$ in weight, his general condition improved and steroid dosage could be reduced and then finally withdrawn by the tenth week. (Doubling of the dose of Lamprene was considered but was not found necessary.) Two weeks later the patient was so much better that he could resume normal activity, including bicycle riding. After 5 months of Lamprene therapy his lesions had subsided remarkably (though heavily pigmented, they left no tissue-paper appearance), weight was increasing, and there was no further oedema. After an initial decline in weight from 
$136 \mathrm{lb}$ to $128 \mathrm{lb}(61.7$ to $58 \mathrm{~kg})$, his weight was up to $141 \mathrm{lb}(64 \mathrm{~kg})$ at the end of the trial.

\section{Group 2}

A.N. 3883, a 32-year-old Fijian female, was first admitted in 1961 suffering from lepromatous leprosy with an average B.I. of $6+$. After 9 months' DDS therapy she developed bronchial asthma, followed by nodular reactions only partially controlled by steroids. Treatment with over $50 \mathrm{mg}$ of DDS weekly then gave rise to ENL reactions. Thiambutosine was tried but proved unsatisfactory, and the patient continued to have periodic ENL reactions, with constant neuritic pains necessitating prolonged steroid therapy. After 9 days of Lamprene treatment her neuritic pain disappeared and, apart from one brief recurrence, there has been no further neuritic pain or ENL reaction; 11 months after starting treatment with Lamprene, steroid therapy was tapered off. The B.I. showed a dramatic response (see Table 2), and she gained $11 \mathrm{lb}(5 \mathrm{~kg})$ in weight.

L.C. 3938, Fijian female, aged 25 years, was admitted with lepromatous leprosy in 1962, with a B.I. of $6.0+$. On a dosage of $200 \mathrm{mg}$ DDS weekly she started developing neuritic pains and ENL reactions after 5 months. These were partially controlled by steroids, a reduction of the dosage of DDS to $10 \mathrm{mg}$ weekly, and then by 9 months on thiambutosine. After $5 \frac{1}{2}$ years of treatment her B.I. had fallen to 3.75, but she was still having neuritic pains and ENI, reactions. Five days after the start of treatment with Lamprene she developed another nodular reaction, but this completely subsided within 12 days. Since then there have been no further reactions, and her lesions have steadily improved.

$J . N$. 3964, male, part Chinese, aged 37 years, was admitted in 1963 with lepromin-positive dimorphous leprosy. The patient's ears were thickened, nodulated and generally puffy and his face slightly puffy with minimal madarosis. The nasal septum was collapsed and ulcerated and there were scars on the upper lip. Both auricular nerves were enlarged, and the ulnar, peroneal and popliteal nerves palpable and tender. Deep indurations were present in both upper and lower extremities accompanied by glove/stocking anaesthesia. The dosage of DDS reached $100 \mathrm{mg}$ twice weekly before reactions and albuminuria interrupted his progress. Parenteral DDS therapy was tried during quiescent periods, with or without steroids, but

TABLE 2

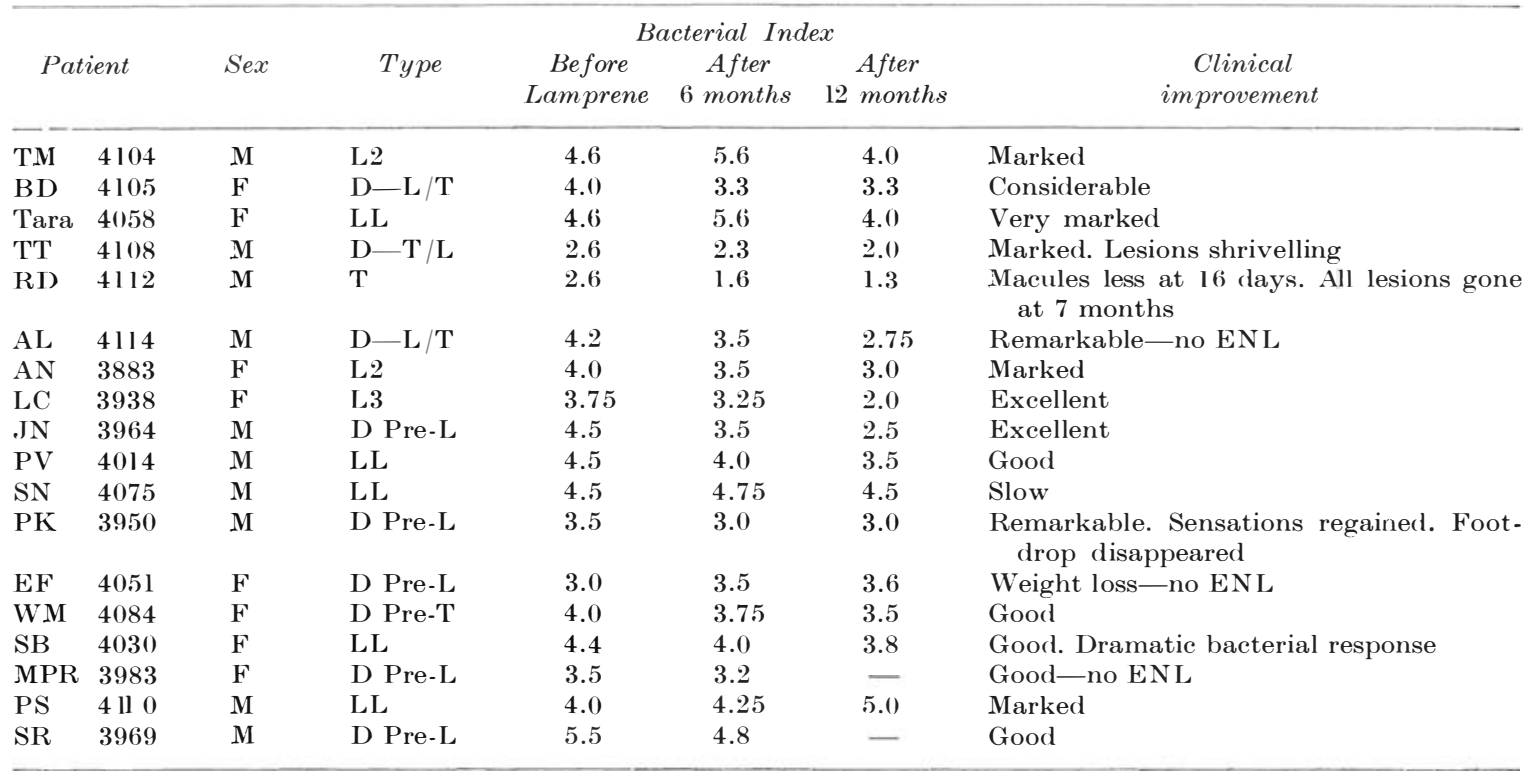


it was a continuous battle. However, 24 days after Lamprene treatment was begun the patient recovered from his last ENL reaction, and he has been steadily improving since. After the fifth month of treatment he was able to referee a football match, and during the sixth month he played volleyball with other patients. After 10 months on Lamprene his grip-strength had increased from 20 to $100 \mathrm{lb}$ (9 to $45 \mathrm{~kg}$ ) (right) and from 15 to $80 \mathrm{lb}(6.8$ to $36 \mathrm{~kg}$ ) (left). Anaesthesia was slowly receding over the back of his legs and forearms.

\section{Group 3}

$P . V .4014$, male Fijian 40 years of age, was first admitted in 1945 with lepromatous leprosy, treated with chaulmoogra oil, and discharged in 1961 on a dose of $200 \mathrm{mg}$ of DDS weekly. He abandoned treatment 2 years later and was then without drugs for 2 years. Thereafter he relapsed and was re-admitted to Makogai in 1964 with lepromatous disease. After restarting DDS therapy he remained on an even keel for 6 months before developing skin irritation on a dosage of $400 \mathrm{mg}$ of DDS weekly. Reduction of the dose to $300 \mathrm{mg}$ weekly and antihistaminic drugs had no effect. A further reduction to $12.5 \mathrm{mg}$ of DISS intramuscularly per week was made, but anaphylaxis continued, the patient becoming weaker and depressed, so that the drug had to be stopped completely. Streptomycin, 1 g daily, proved beneficial, but 5 months later he was given Lamprene instead, and since then there has been steady improvement. Irritation subsided, appetite improved, nerve pains cleared, he became physically active, and weight increased from 180 to 193 lb (81.6 to $87.5 \mathrm{~kg})$.

S.N. 4075, male Fijian aged 31 years, was discharged from Tamavua Tuberculosis Hospital in March 1950 and admitted to Makogai Hospital 14 days later with lepromatous leprosy. After successful DDS therapy he was discharged in 1959. At first he continued to take $200 \mathrm{mg}$ of DDS per week at home, but for some 18 to 20 months before his re-admission in 1966 with diffuse lepromatous leprosy he had taken none. Despite a low dosage of DDS when treatment restarted, he developed reactions requiring long periods in hospital and prolonged steroid therapy. Even when DDS was replaced by streptomycin, frequent ENL episodes persisted and the B.I. rose from 4.0 to 4.5 . The clinical response to Lamprene was slow and less dramatic than in the other patients, but during the first 5 months of treatment he suffered only 2 bouts of mild ENL reaction, after the second of which he was weaned off steroids. Three more mild attacks of ENL during the following 7 months were controlled by short courses of steroids.

P.K. 3950, male Fijian aged 57, first admitted to Makogai in 1941 with lepromatous leprosy, had responded to amithiazone, but was allergic (manifested by exfoliative dermatitis) to this and several other drugs, and had a history of ENL. As a result, his B.I. (up from 3.0 to 3.5) and clinical condition had deteriorated. After 2 months of treatment with Lamprene his lesions were clearly receding; the nodules were flattening, and it was clear that Lamprene was the right drug for the long-standing and resistant disease in this patient. During the thirteenth week some nodules became almost as flat as normal skin, but most striking of all was the disappearance during the sixth month of an earlier right foot drop.

E.F. 4051, female Rotuman aged 59 years, was first admitted in 1937 with neural disease, was re-admitted in 1945 with lepromatous leprosy for which she was treated with IDDS, and discharged in 1958. The patient confessed to being very irregular in taking her pills at home. She relapsed again and was admitted a third time with dimorphous leprosy. The second relapse was ushered in by severe irritation all over her body which seems to have been an anaphylactic reaction to a single large dose of DDS. On her third admission, the B.I. was only 0.75 . Standard doses of DISS were tried, but her B.I. went up to 3.0 and the patient was then given Lamprene. She tolerated this drug well and her lesions cleared, but the B.I. is still rising. This phenomenon is still not fully understood, but it may be related to increasing 
bacterial density in a shrinking granuloma. Probably because of polyuria, profuse sweating and her great activity, this patient has lost $23 \mathrm{lb}(10.4 \mathrm{~kg})$ in weight in 12 months.

W.M. 4084, female Fijian aged 38 years, was first admitted in 1945 with lepromatous leprosy and treated with chaulmoogra oil until 1958. The patient relapsed in 1962 but responded well to standard doses of DDS. She relapsed again less than 2 years later, however, and the disease was classified as dimorphous. She could not tolerate even small doses of I)DS and had repeated reactions, for which steroids were given. Her B.I. on this third admission was 2.0, but it had increased to 4.0 by the time Lamprene was started. Thereafter her clinical response was slow but steady. She had 2 more reactions towards the end of the sixth month of the trial but was finally weaned off steroids in the eighth month.

S.B. 4030, a 51 year old Indian woman, was first admitted with lepromatous leprosy in 1941 . Treated at first with chaulmoogra oil and later with DDS, she was finally discharged in 1963 . She failed however to continue treatment at home and ultimately relapsed. On her second admission in 1965 she was again treated with DDS, but her condition became progressively worse, with leprides appearing on the trunk and numerous nodules over the buttocks. DDS was discontinued and thiacetazone tried, but this caused depression and was ultimately replaced by Lamprene. The initial clinical response to the latter was good, with increased appetite and general well-being but her condition later appeared to be stationary for some months. However, during the second half of the trial period the response became more evident and the lesions receded markedly.

M.P.R. (T) 3983, a female Samoan aged 30 years, had spent the 10 years 1946-56 in Makogai with lepromatous leprosy. Some 2 years after discharge irregularity in taking her drug had resulted in relapse of the leprosy, now of dimorphous type, and she suffered from episodes of ENL on restarting treatment in 1964 so that the dosage had to be reduced and steroids given in addition. Thiambutosine was also given, but had to be discontinued because of severe depression. Clinical improvement was noted from the very first week of starting treatment with Lamprene. No ENL recurred and steroids could be withdrawn 2 months later. The patient was physically active and gaining weight.

P.S. 4110, an Indian male 46 years old, was first admitted to Makogai in December 1948 with lepromatous leprosy and discharged in 1962. After irregularity in taking DDS the patient relapsed, was re-admitted to hospital in August 1967, and put on treatment with Lamprene 5 days later. After 3 months' chemotherapy his nodules receded markedly, with tissue-paper formation of the overlying skin. No ENL reaction was encountered throughout the period of trial, and the patient gained $12 \mathrm{lb}$ $(5.4 \mathrm{~kg})$ in weight, though the B.I. is still rising. Closer observation is being carried out in this patient to evaluate why the B.I. is rising, although once again reduction of swelling may be the explanation.

S.R. 3969, male Indian aged 43 years, was originally admitted to Makogai in 1943 with lepromatous leprosy. Treated with chaulmoogra oil and later with DDS, he was discharged in 1955 but later relapsed as a result of defaulting on DDS treatment and was re-admitted to Makogai in October 1963. On re-admission he showed the 2 characteristic polar types of leprosy. Treatment with DDS was reinstituted with slowly increasing doses, but 2 years later, on a dosage of $800 \mathrm{mg}$ weekly, he began to have nodular reactions and neuritic pains. Dosage was reduced to $20 \mathrm{mg}$ per week and DDS finally discontinued in 1967, steroids being given periodically to control reactions. Before starting Lamprene the B.I. had reached 5.5 and he required constant nursing in bed. During 11 months of observation this patient had only 2 mild attacks of ENL ( 4 and 16 weeks after starting Lamprene). Steroids were ultimately withdrawn after 6 months. Lesions on the arms, legs, body and face are receding well and the patient is now doing strenuous 
road maintenance work. His B.I. (see Table 2) declined to 4.8 after 6 months of treatment with Lamprene.

\section{SUMMARY AND CONCLUSION}

Of 18 patients suffering from all types of leprosy who have been treated with Lamprene for 12 months, 6 had received no previous treatment, while the remaining 12 had proved either intolerant or resistant to other forms of therapy. One patient responded poorly, but all the others improved during Lamprene therapy, the response being dramatic in several cases (see Table 2).

This trial confirms that Lamprene is the most exciting new drug to be introduced into the treatment of leprosy since the advent of DDS. It is not a "miracle drug"- the fact that no patient's disease was arrested after 12 months of continuous therapy proves that-but it is a most effective aid to treatment. For patients with ENL or those unable to tolerate DDS, Lamprene is undoubtedly an excellent substitute. It may, indeed, save their lives. However, it is as yet uncertain whether Lamprene will prove the better long-term drug in patients who can take DDS.

No resistance to Lamprene appeared in the 12-month period, but further trials are required to ascertain whether resistance will develop at a later date. Studies are also needed to determine whether patients who suffer from ENL during treatment with DDS can safely revert to that drug after a period of Lamprene therapy and subsidence of the acute reaction. It would also be interesting to know whether DDS and Lamprene have a synergistic effect, that is, whether patients receiving both drugs do better than those treated with either drug by itself.

\section{ACKNOWLEDGEMENTS}

My thanks are due to Messrs. Geigy Pharmaceuticals S.A. for supplies of Lamprene, and to Dr. Th. Ahrens of Geigy, Basle, for his assistance, advice and interest throughout the trial.

I am also indebted to Dr. C. H. Gurd, Director of Medical Services, Fiji, for permission to publish; to Dr. D. W. Beckett, Assistant Director of Medical Services, for the summary and conclusion, and to the nursing Sisters for their encouragement and help.

\section{REFERENCE}

RIDLEY, D. S. (1967). The evaluation of drugs for leprosy: biological considerations. Trans. $R$. Ses. trop. Med. Hyg. 61, 596. 